\title{
Profil Keamanan setelah Pemberian Dosis Primer Vaksin Pentabio® pada Bayi di Indonesia
}

\author{
Julitasari Sundoro, ${ }^{1}$ Kusnandi Rusmil, ${ }^{2}$ Mei Neni Sitaresmi, ${ }^{3}$ Arhana, ${ }^{4}$ I.G.G. Djelantik, ${ }^{5}$ \\ Sri Rezeki Hadinegoro, ${ }^{1}$ Hindra Irawan Satari, ${ }^{1}$ Syafriyal, ${ }^{1}$ Novilia Sjafri Bachtiar, ${ }^{6}$ Rini Mulia Sari ${ }^{7}$ \\ ${ }^{1}$ Komite Nasional Pengkajian dan Penanggulangan Kejadian Ikutan Pasca Imunisasi (KOMNAS PP-KIPI), ${ }^{2}$ Komite \\ Daerah Pengkajian dan Penanggulangan Kejadian Ikutan Pasca Imunisasi Jawa Barat (KOMDA PP-KIPI Jawa \\ Barat), ${ }^{3}$ KOMDA PP-KIPI Yogyakarta, ${ }^{4}$ KOMDA PP-KIPI Bali, ${ }^{5}$ KOMDA PP-KIPI Nusa Tenggara Barat, ${ }^{6}$ PT. Bio \\ Farma, ${ }^{7}$ Program Studi Magister Ilmu Kedokteran Dasar Fakultas Kedokteran Universitas Padjadjaran
}

\begin{abstract}
Abstrak
Vaksin Hib mulai digunakan pada Pogram Imunisasi Nasional sejak tahun 2013 secara bertahap dan di seluruh Indonesia mulai tahun 2014 dalam bentuk vaksin kombinasi DTP/HB/Hib (Pentabio ${ }^{\circledR}$ ), yang memberikan kekebalan terhadap difteria, pertusis, tetanus, hepatitis B, dan Haemophilus influenzae tipe b. Studi ini menilai reaksi sitemik, reaksi lokal, dan reaksi yang serius pascaimunisasi dengan Pentabio ${ }^{\circledR}$. Sebanyak 4.000 bayi penerima vaksin Pentabio ${ }^{\circledR}$ bergabung dalam studi ini. Reaksi yang timbul dicatat pada kartu harian oleh petugas yang sudah dilatih. Vaksin Pentabio ${ }^{\circledR}$ yang diamati pada PMS ini menggunakan vaksin rutin dari Program Imunisasi Nasional dalam waktu pengamatan 28 hari di empat propinsi, yaitu Nusa Tenggara Barat, Bali, Yogyakarta, dan Jawa Barat pada periode Mei-Desember 2014. Sebanyak 3.978 data dapat dianalisis karena 22 di antaranya tidak memberikan informasi yang valid. Reaksi sistemik yang paling banyak timbul adalah demam $0,85 \%$ pada 30 menit pertama, dan meningkat menjadi 14,03\% pada satu hari pascaimunisasi, kemudian sembuh pada hari berikutnya. Reaksi lokal yang paling sering timbul adalah nyeri pada tempat suntikan pada $67,6 \%$ subjek pada 30 menit setelah imunisasi, dan meningkat menjadi 87,23\% pada 1 hari pascaimunisasi namun sembuh pada hari berikutnya. Mayoritas nyeri yang timbul adalah kategori ringan. Tidak ditemukan kejadian ikutan pascaimunisasi serius selama pengamatan. Simpulan, reaksi lokal dan sistemik pascaimunisasi dengan Pentabio $^{\circledR}$ dapat ditoleransi pada bayi. [MKB. 2017;49(2):86-93]
\end{abstract}

Kata kunci: Bayi, Pentabio®, post marketing surveillance, reaksi lokal, reaksi sistemik

\section{Safety Profile Following Pentabio® Primary Dose Vaccination in Indonesian Infants}

\begin{abstract}
Since 2013 Indonesian Expanded Program on Immunization (EPI) has graduallyincluded Hib vaccine into routine EPI schedule in four provinces and has established the vaccine inclusion in the the nationwide program through integration of $\mathrm{Hib}$ vaccine into existing DTP/HB vaccine in the form of pentavalent vaccine (DTP/HB/ $\mathrm{Hib}$ ). Pentabio ${ }^{\circledR}$ vaccine is given to provide protection against diphtheria, tetanus, pertussis, hepatitis $B$, and Hib infection in infants and children under 5 years old. The objective of this study was to assess the systemic reactions, local reactions, and any serious adverse event after Pentabio ${ }^{\circledR}$ immunization. About 4,000 infants were involved in this study. Systemic and local reactions were recorded on diary cards by trained health care provider. Pentabio $®$ vaccines in this PMS were obtained from the National Immunization Program within 28 days of observation in four provinces, West Nusa Tenggara, Bali, Yogyakarta, and West Java in May-December 2014. In total, 3,978 infants were analyzed, while the other 22 forms were not included due to incomplete information. The most common systemic reaction was fever, found in $0.85 \%$ of the subjects at 30 minutes after injection, and increased to $14.03 \%$ at day 1 (one) after immunization, which disappeared the day after. The most common local reaction was pain, which was found in $67.6 \%$ subjects at 30 minutes after injection, and increased to $87.23 \%$ at day 1 (one) after immunization to disappear the day after. The intensity of the pain was mostly mild. No serious adverse event following immunization found during observation. [MKB. 2017;49(2):86-93]
\end{abstract}

Key words: Infants, local reactions, Pentabio ${ }$, post marketing surveillance, systemic reactions

Korespondensi: Dr. Julitasari Sundoro, dr., MSc-PH, Komite Nasional Pengkajian dan Penanggulangan Kejadian Ikutan Pasca Imunisasi (KOMNAS PP-KIPI), E-mail: julitasari.sundoro@gmail.com 


\section{Pendahuluan}

Pada tahun 2011, sudah 177 (91\%) negara menerapkan imunisasi 3 (tiga) dosis vaksin Haemophilus influenzae tipe b (Hib) di dunia. SEARO/WHO dan ITAGI merekomendasikan agar Indonesia memasukkan vaksin Hib dalam program imunisasi nasional. ${ }^{1,2}$

Indonesia termasuk ke dalam 15 negara yang diprediksi mempunyai jumlah episode pneumonia tinggi, yaitu pada urutan keenam. ${ }^{3}$ Sebuah studi yang dilakukan di Pulau Lombok memperlihatkan bahwa vaksinasi Hib akan menurunkan beban penyakit dan kematian pada anak di Indonesia. ${ }^{4} \mathrm{Hal}$ ini menunjukkan bahwa vaksin ini akan sangat bermanfaat pada golongan usia bayi dan balita.

Karena jadwal pemberian imunisasi Hib sama dengan vaksin DTwP/HB maka alternatif pemberian vaksin Hib yang paling baik adalah penggabungan menjadi vaksin kombinasi DTwP/ HB/Hib. Untuk itu Bio Farma mengembangkan vaksin kombinasi DTwP/HB/Hib untuk dapat diberikan pada bayi yang pada fase I vaksin Hib ini pada orang dewasa terbukti aman. ${ }^{5}$ Setelah uji klinis fase I untuk vaksin Hib, dilanjutkan dengan uji klinis vaksin DTwP/HB/Hib pada bayi sebanyak 3 dosis dengan interval 1 bulan, pada fase I, II, dan III. Ketiga fase menunjukkan bahwa vaksin ini aman dan imunogenik untuk diberikan pada bayi sebagai dosis primer. ${ }^{6-8}$ Pembuatan vaksin kombinasi ini sangat membantu, karena bila vaksin Hib diberikan secara terpisah dengan DTwP/HB, berarti akan terjadi pemberian dua suntikan sekaligus akan tidak nyaman pada bayi serta biaya yang diperlukan menjadilebih mahal. Vaksin pentavalen DTwP/HB/Hib akan menghemat biaya, lebih disukai, juga efisien dalam penyiapan logistik. Vaksin kombinasi DTwP/HB /Hib (Pentabio ${ }^{\circledR}$ ) sudah diregistrasi di Badan POM serta mendapat ijin edar pada tahun 2013.

Penelitian ini bertujuan mengevaluasi reaksi yang timbul pascaimunisasi vaksin DTwP/HB /Hib (Pentabio ${ }^{\circledR}$ ) pada bayi pascapemasaran, baik reaksi sistemik maupun reaksi lokal sekitar tempat suntikan.

\section{Metode}

Penelitian ini merupakan penelitian kohort yang prospektif menggunakan analisis deskriptif dengan pengamatan reaksi sistemik dan lokal terhadap bayi setelah menerima 1 dosis vaksin Pentabio $^{\circledR}$ dalam waktu pengamatan 28 hari di empat propinsi, yaitu Nusa Tenggara Barat, Bali, Yogyakarta, dan Jawa Barat pada periode MeiDesember 2014. Keempat propinsi ini dipilih karena di sinilah pertama kali vaksin DTwP/HB $/$ Hib (Pentabio ${ }^{\circledR}$ ) dipergunakan di Indonesia. Persetujuan etik telah diperoleh dari Komite Etik Penelitian Kesehatan Fakultas Kedokteran UIRSCM, Jakarta Nomor 107/H2F1/ETIK/2014.

Jumlah subjek dihitung menggunakan rumus untuk PMS (Uji Klinis fase IV) dari kejadian ikutan yang telah diketahui. Suhu $>40,5^{\circ} \mathrm{C}$ sebesar $0,3 \%$ yang terjadi setelah imunisasi dengan vaksin berbasis DTP. Jumlah subjek minimal adalah 3.310 subjek dengan perkiraan drop out (DO) ditambah sekitar 20\% menjadi 4.000 subjek. Kriteria inklusi adalah bayi yang menerima setidaknya 1 dosis vaksin Pentabio ${ }^{\circledR}$ dari Program Imunisasi Nasional. Orangtua telah mendapat penjelasan mengenai penelitian dan setuju bayinya terlibat dalam penelitian ini dengan menandatangani lembar persetujuan setelah penjelasan. Kriteria eksklusi adalah menerima vaksin lain dalam interval 1 bulan kecuali vaksin oral polio vaccine (OPV) atau inactivated polio vaccine (IPV).

Reaksi lokal dan sistemik dicatat pada kartu harian pada 30 menit, 72 jam, hingga 28 hari setelah imunisasi. Pengamatan reaksi yang timbul dilakukan oleh orangtua dan dikonfirmasi oleh petugas kesehatan yang datang ke rumah 72 jam pascaimunisasi yang sebelumnya telah mendapatkan pelatihan mengenai penelitian ini dan cara melakukan pengamatan terhadap reaksi yang timbul.

Reaksi sistemik adalah semua reaksi yang timbul secara sistemik pascaimunisasi, dapat berupa demam, rewel atau iritabilitas. Suhu tubuh yang dimasukkan sebagai demam pasca imunisasi adalah $\geq 38^{\circ} \mathrm{C} .{ }^{9}$ Kategori demam dibagi 3 , demam ringan $38,0-38,4^{\circ} \mathrm{C}$; demam sedang $38,5-38,9^{\circ} \mathrm{C}$; dan demam berat $\geq 39^{\circ} \mathrm{C}$. Reaksi sistemik rewel, diukur berdasar atas intensitasnya, ringan bila menangis lebih dari biasanya dengan nada yang normal; sedang bila bayi menangis dengan nada tinggi; berat bila bayi menangis tanpa dapat dihentikan selama paling sedikit 3 jam.

Reaksi lokal adalah reaksi yang timbul pada dan sekitar tempat suntikan. Reaksi lokal yang diamati adalah nyeri, kemerahan, serta pembengkakan pada bekas suntikan serta reaksi lokal lainnya bila ada. Rasa nyeri dikelompokkan berdasar atas tingkat keparahannya; ringan, bayi bereaksi bila tempat suntikan disentuh; sedang, bayi menangis bila tempat suntikan disentuh; berat, bila bayi menangis saat tungkai 
Julitasari Sundoro: Profil Keamanan setelah Pemberian Dosis Primer Vaksin Pentabio® pada Bayi di Indonesia

Tabel 1 Distribusi Subjek Menurut Usia dan Dosis Pentabio ${ }^{\circledR}$

\begin{tabular}{ccccccc}
\hline \multirow{2}{*}{$\begin{array}{c}\text { Usia } \\
\text { (bulan) }\end{array}$} & \multicolumn{2}{c}{ Pentabio $^{\circledR} \mathbf{1}$} & \multicolumn{2}{c}{ Pentabio $^{\circledR} \mathbf{2}$} & \multicolumn{2}{c}{ Pentabio $^{\circledR} \mathbf{3}$} \\
\cline { 2 - 7 } & $\mathbf{n}$ & $\mathbf{0}$ & $\mathbf{n}$ & $\mathbf{\%}$ & $\mathbf{n}$ & $\mathbf{\%}$ \\
\hline 2 & 1.060 & 26,65 & 0 & 0 & 0 & 0 \\
3 & 206 & 5,18 & 810 & 20,36 & 51 & 1,28 \\
4 & 38 & 0,96 & 298 & 7,49 & 683 & 17,17 \\
5 & 18 & 0,45 & 54 & 1,36 & 455 & 11,44 \\
6 & 11 & 0,28 & 16 & 0,4 & 147 & 3,7 \\
7 & 3 & 0,08 & 9 & 0,23 & 59 & 1,48 \\
8 & 0 & 0 & 2 & 0,05 & 29 & 0,73 \\
9 & 0 & 0 & 2 & 0,05 & 14 & 0,35 \\
10 & 0 & 0 & 0 & 0 & 10 & 0,25 \\
11 & 0 & 0 & 0 & 0 & 3 & 0,08 \\
\hline
\end{tabular}

digerakkan. Kemerahan dan pembengkakan yang timbul diukur mempergunakan gelang plastik (plastic bangle) dengan kategori tingkat keparahan sebagai berikut; ringan $<2,5 \mathrm{~cm}$; sedang 2,5-5 $\mathrm{cm}$; dan berat $>5 \mathrm{~cm}$ dari diameter terlebar. ${ }^{10,11}$

\section{Hasil}

Sebanyak 3.978 bayi mempunyai data lengkap dan dapat dianalisis. Sebanyak 22 data tidak dapat dianalisis karena diisi secara tidak lengkap. Yogyakarta dan Nusa Tenggara Barat berhasil dengan kelengkapan data 100\%, sedangkan Jawa Barat 99,9\% dan Bali 97,9\%. Namun demikian, jumlah subjek masih melebihi syarat minimal studi ini.

Usia subjek dalam penelitian ini diketahui dengan rata-rata 3,54 simpangan baku 1,39 dengan usia antara 2 hingga 11 bulan. Selama penelitian ini berlangsung, tidak ditemukan laporan KIPI serius. Dua kejadian sistemik tersering adalah demam dan juga rewel, dengan

Tabel 2 Distribusi Subjek Menurut Tingkatan Demam, Waktu Pengamatan, dan Imunisasi Pentabio $^{\circledR}$ ke-1, ke-2, dan ke-3

\begin{tabular}{|c|c|c|c|c|c|c|c|c|c|c|}
\hline \multirow{2}{*}{$\begin{array}{l}\text { Klasifikasi } \\
\text { Demam/Pentabio }\end{array}$} & \multicolumn{2}{|c|}{30 Menit } & \multicolumn{2}{|c|}{ Hari ke-1 } & \multicolumn{2}{|c|}{ Hari Ke-2 } & \multicolumn{2}{|c|}{ Hari ke-3 } & \multicolumn{2}{|c|}{$\begin{array}{c}\text { Hari ke } \\
4-28 \\
\end{array}$} \\
\hline & $\mathbf{n}$ & $\%$ & $\mathbf{n}$ & $\%$ & $\mathbf{n}$ & $\%$ & $\mathbf{n}$ & $\%$ & $\mathbf{n}$ & $\%$ \\
\hline Pentabio 1 & 7 & 0,18 & 224 & 5,63 & 43 & 1,08 & 7 & 0,18 & 6 & 0,16 \\
\hline Ringan & 5 & 0,13 & 184 & 4,63 & 39 & 0,98 & 6 & 0,15 & 3 & 0,08 \\
\hline Sedang & 2 & 0,05 & 34 & 0,85 & 4 & 0,10 & 1 & 0,03 & 1 & 0,03 \\
\hline Berat & 0 & 0,00 & 6 & 0,15 & 0 & 0,00 & 0 & 0,00 & 2 & 0,05 \\
\hline Pentabio 2 & 11 & 0,28 & 153 & 3,85 & 43 & 1,08 & 56 & 1,41 & 15 & 0,38 \\
\hline Ringan & 9 & 0,23 & 126 & 3,17 & 39 & 0,98 & 44 & 1,11 & 9 & 0,23 \\
\hline Sedang & 2 & 0,05 & 23 & 0,58 & 4 & 0,10 & 8 & 0,20 & 4 & 0,10 \\
\hline Berat & 0 & 0,00 & 4 & 0,10 & 0 & 0,00 & 4 & 0,10 & 2 & 0,05 \\
\hline Pentabio 3 & 16 & 0,4 & 181 & 4,55 & 43 & 1,08 & 34 & 0,85 & 25 & 0,64 \\
\hline Ringan & 10 & 0,25 & 149 & 3,75 & 39 & 0,98 & 29 & 0,73 & 19 & 0,48 \\
\hline Sedang & 6 & 0,15 & 21 & 0,53 & 4 & 0,10 & 3 & 0,08 & 5 & 0,13 \\
\hline Berat & 0 & 0,00 & 11 & 0,28 & 0 & 0,00 & 2 & 0,05 & 1 & 0,03 \\
\hline Total & 34 & 0,85 & 558 & 14 & 129 & 3,24 & 97 & 2,44 & 46 & 1,18 \\
\hline
\end{tabular}


Tabel 3 Kejadian Sitemik Lain

\begin{tabular}{lcccccccc}
\hline & \multicolumn{9}{c}{ Kejadian Lain-Lain } \\
\cline { 2 - 10 } Gejala/Penyakit & \multicolumn{1}{c}{ Frekuensi } & $\begin{array}{c}\text { Lama Rata-rata } \\
\text { Sakit/Hari }\end{array}$ & \multicolumn{2}{c}{ Sembuh } & \multicolumn{2}{c}{ Tidak Sembuh } \\
\cline { 2 - 10 } & $\mathbf{n}$ & $\mathbf{9}$ & $\mathbf{n}$ & $\mathbf{\%}$ & $\mathbf{n}$ & $\mathbf{\%}$ & $\mathbf{n}$ & \% \\
\hline Dermatitis & 1 & 0,03 & 1 & 0,03 & 1 & 0,03 & 0 & 0,00 \\
Diare & 66 & 1,66 & 66 & 1,66 & 66 & 1,66 & 0 & 0,00 \\
Diare, ISPA & 6 & 0,15 & 6 & 0,15 & 6 & 0,15 & 0 & 0,00 \\
ISPA & 65 & 1,63 & 65 & 1,63 & 65 & 1,63 & 0 & 0,00 \\
Muntah & 34 & 0,85 & 34 & 0,85 & 34 & 0,85 & 0 & 0,00 \\
Rash & 3 & 0,08 & 3 & 0,08 & 3 & 0,08 & 0 & 0,00 \\
Total & 175 & 4,40 & 175 & 4,40 & 175 & 4,40 & 0 & 0,00 \\
\hline
\end{tabular}

gambaran sebagai berikut.

Berdasar atas tingkatan dan waktu kejadian, reaksi demam yang diketahui tertinggi adalah demam ringan yang terjadi pada satu hari sesudah imunisasi. Berdasarkan pemberian imunisasi Pentabio ${ }^{\circledR}$ ke-1, 2 dan 3, kejadian demam ringan terbanyak pada hari pertama setelah imunisasi Pentabio ${ }^{\circledR}$ ke-1, diikuti dengan setelah imunisasi pentabio ${ }^{\circledR}$ ke-3. Tidak ditemukan demam dengan kategori berat.

Kejadian rewel tertinggi adalah pada hari ke-1 setelah pemberian Pentabio ${ }^{\circledR}$ ke-1. Namun, mayoritas kejadian rewel tersebut adalah ringan, tidak ditemukan adanya kejadian rewel yang berat. Kejadian sistemik lain tertera pada Tabel 3.

Kejadian sistemik lain terbanyak adalah diare sebesar 1,66\% disusul dengan infeksi saluran pernapasan atas (ISPA) sebesar 1,63\%. Semua kejadian sistemikdi atas tidak ada yang menetap.

Pada Tabel 4, nyeri lokal terbanyak adalah pada hari ke-1 setelah pemberian Pentabio ${ }^{\circledR} \mathrm{ke}-1$, disusul dengan hari ke-1 setelah pemberian Pentabio ${ }^{\circledR}$ ke-3. Mayoritas nyeri yang timbul

Tabel 4 Distribusi Tingkatan Nyei Lokal Menurut Waktu Pengamatan dan Imunisasi Pentabio ${ }^{\circledR}$ ke-1, ke-2, dan ke-3

\begin{tabular}{ccccccccccc}
\hline \multirow{2}{*}{ Nyeri Lokal/ Pentabio } & \multicolumn{2}{c}{$\mathbf{3 0}$ Menit } & \multicolumn{2}{c}{ Hari ke-1 } & \multicolumn{2}{c}{ Hari ke-2 } & \multicolumn{2}{c}{ Hari ke-3 } & \multicolumn{2}{c}{ Hari ke- } \\
\cline { 2 - 12 } & $\mathbf{n}$ & $\mathbf{9}$ & $\mathbf{n}$ & $\mathbf{\%}$ & $\mathbf{n}$ & $\mathbf{\%}$ & $\mathbf{n}$ & $\mathbf{\%}$ & $\mathbf{n}$ & $\mathbf{\%}$ \\
\hline Pentabio1 & 991 & 24,91 & 1238 & 31,12 & 506 & 12,72 & 175 & 4,399 & 63 & 1,584 \\
Nyeri lokal ringan & 560 & 14,08 & 626 & 15,74 & 295 & 7,42 & 122 & 3,07 & 48 & 1,21 \\
Nyeri lokal sedang & 280 & 7,04 & 377 & 9,48 & 133 & 3,34 & 32 & 0,80 & 10 & 0,25 \\
Nyeri lokal berat & 151 & 3,80 & 235 & 5,91 & 78 & 1,96 & 21 & 0,53 & 5 & 0,13 \\
Pentabio 2 & 834 & 20,97 & 1042 & 26,19 & 454 & 11,41 & 136 & 3,419 & 41 & 1,031 \\
Nyeri lokal ringan & 468 & 11,76 & 535 & 13,45 & 263 & 6,61 & 99 & 2,49 & 29 & 0,73 \\
Nyeri lokal sedang & 243 & 6,11 & 309 & 7,77 & 114 & 2,87 & 24 & 0,60 & 5 & 0,13 \\
Nyeri lokal berat & 123 & 3,09 & 198 & 4,98 & 77 & 1,94 & 13 & 0,33 & 7 & 0,18 \\
Pentabio 3 & 864 & 21,72 & 1190 & 29,91 & 490 & 12,32 & 147 & 3,695 & 53 & 1,332 \\
Nyeri lokal ringan & 525 & 13,20 & 647 & 16,26 & 290 & 7,29 & 105 & 2,64 & 37 & 0,93 \\
Nyeri lokal sedang & 233 & 5,86 & 351 & 8,82 & 127 & 3,19 & 26 & 0,65 & 10 & 0,25 \\
Nyeri lokal berat & 106 & 2,66 & 192 & 4,83 & 73 & 1,84 & 16 & 0,40 & 6 & 0,15 \\
\hline
\end{tabular}




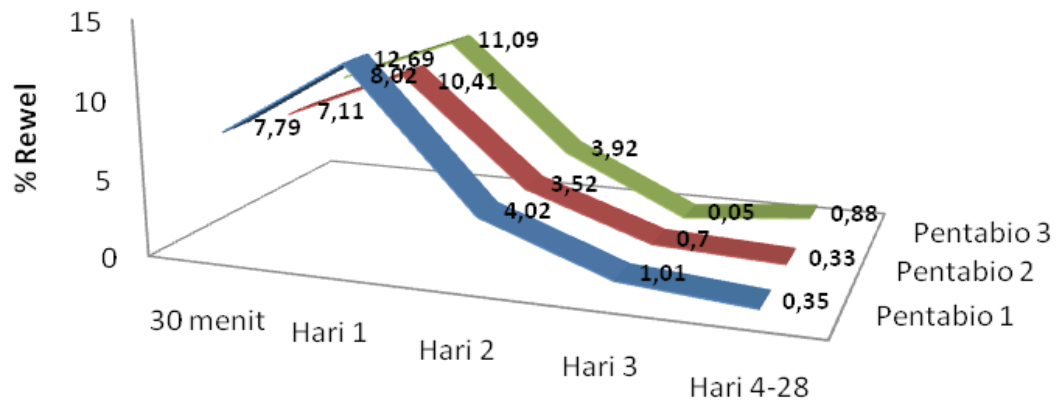

\begin{tabular}{|l|c|c|c|c|c|}
\cline { 2 - 6 } \multicolumn{1}{c|}{} & 30 menit & Hari 1 & Hari 2 & Hari 3 & Hari 4-28 \\
\hline Pentabio 1 & 7,79 & 12,69 & 4,02 & 1,01 & 0,35 \\
\hline Pentabio 2 & 7,11 & 10,41 & 3,52 & 0,7 & 0,33 \\
\hline Pentabio 3 & 8,02 & 11,09 & 3,92 & 0,05 & 0,88 \\
\hline
\end{tabular}

Gambar 1 Grafik Kejadian Rewel Menurut Pemberian Pentabio ${ }^{\circledR}$ ke-1, ke-2, dan ke-3

adalah ringan nyeri lokal berat timbul pada 0,13-5,91\% subjek.

Kasus pembengkakan paling banyak adalah hari ke-1 setelah pemberian Pentabio ${ }^{\circledR}$ ke-3, kemudian disusul dengan hari ke-1 setelah pemberian Pentabio ${ }^{\circledR}$ yang pertama. Sama dengan reaksi lokal lainnya, untuk pembengkakan juga mayoritas ringan (Gambar 2).

Untuk reaksi lokal kemerahan, ditemukan tidak sebanyak reaksi lokal lainnya. Kemerahan paling banyak adalah pada hari ke-1 setelah pemberian Pentabio $^{\circledast}$ ke-1, disusul dengan setelah Pentabio ${ }^{\circledR}$ ke-3. Namun, angka dari ketiganya tidak berbeda jauh, 6,89-7,52\%. Sama seperti reaksi lokal lainnya, kemerahan juga didominasi oleh kategori ringan 1,31-7,21\%.

\section{Pembahasan}

Tidak ditemukan KIPI yang serius baik pada pengamatan 30 menit pertama pascaimunisasi,

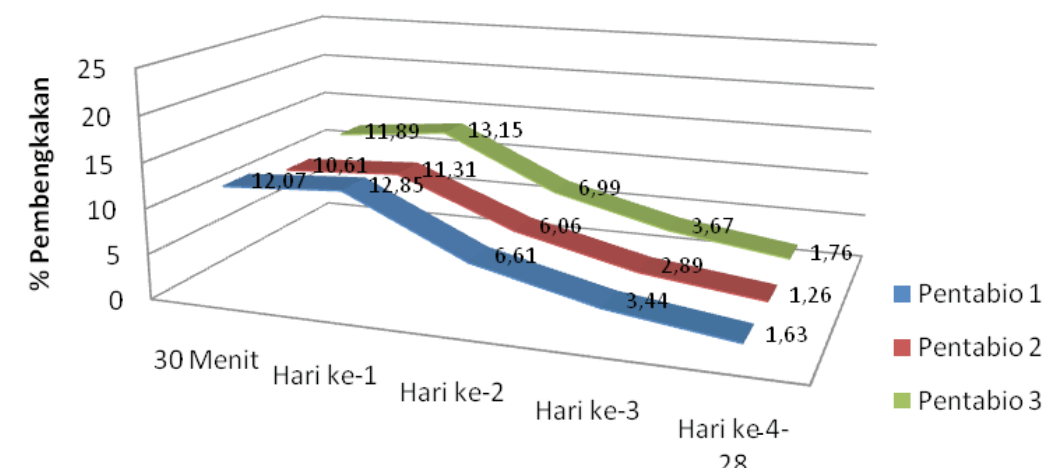

\begin{tabular}{|l|c|c|c|c|c|}
\cline { 2 - 6 } \multicolumn{1}{c|}{} & 30 Menit & Hari ke-1 & Hari ke-2 & Hari ke-3 & $\begin{array}{c}\text { Hari ke 4- } \\
28\end{array}$ \\
\hline — Pentabio 1 & 12,07 & 12,85 & 6,61 & 3,44 & 1,63
\end{tabular}

\section{Gambar 2 Grafik Pembengkakan Menurut Waktu Pengamatan dan Imunisasi Pentabio}


maupun hingga 28 hari pascaimunisasi Pentabio ${ }^{\circledR}$ pada penelitian ini. Mengacu kepada studi lain yang dilakukan di Guatemala pascaintroduksi vaksin pentavalen yang melibatkan 3.000 bayi menemukan 10 KIPI pada 8 orang bayi, 4 di antaranya merupakan KIPI serius yang berhubungan dengan vaksin. Terdapat 13 kematian akibat penyakit yang biasa timbul pada bayi dan dinyatakan tidak berhubungan dengan vaksinasi. ${ }^{12}$

Angka kejadian demam pada setiap kali pengamatan bervariasi antara 0,85 sampai $14,03 \%$. Paling tinggi pada hari ke-1 setelah imunisasi (14,03\%) dengan angka kejadian demam yang tertinggi adalah demam ringan $(11,54 \%)$. Pada literatur WHO mengenai "Supplementary Information on Vaccine Safety" dinyatakan bahwa reaksi sistemik demam setelah imunisasi vaksin yang mengandung DTwP mencapai 50\%. Pada uji klinis Fase I, II, dan III vaksin DTP/HB/Hib yang dilakukan sebelumnya didapatkan kejadian demam yang lebih tinggi hingga lebih dari20\% dalam 72 jam setelah imunisasi. ${ }^{6-8}$ Sebuah studi PMS di Havana, Kuba yang melibatkan 4.059 bayi menemukan demam sebanyak $44,2 \%$ dan demam ringan $15,7 \%$ mendekati angka yang tercantum dalam literatur WHO.$^{13}$ Studi PMS di India menemukan kejadian demam pascaPMS vaksin pentavalen pada 1.510 bayi adalah 11,2-14,0\%, mirip dengan yang ditemukan pada studi ini. ${ }^{14}$ Studi PMS di Guatemala, tidak menyampaikan secara detail jenis KIPI yang timbul. Dengan demikian, kejadian demam yang ditemukan pada penelitian ini jauh lebih kecil dibanding dengan kejadian demam pada uji klinis vaksin ini, literatur WHO, dan laporan pada studi di Havana, namun mirip dengan studi di India. ${ }^{6-8,12-14}$

Angka kejadian rewel tertinggi diketahui pada pengamatan satu hari setelah pemberian imunisasi yaitu, sebesar $1.360 \quad(34,19 \%)$ dan selanjutnya kejadian rewel menurun pada hari berikutnya. Berdasar atas pengamatan, kejadian rewel diketahui terbanyak adalah rewel ringan sebesar $33,28 \%$ yang terjadi pada satu hari setelah imunisasi dan menurun pada hari berikutnya.

Menurut literatur dari WHO mengenai "Supplementary Information on Vaccine Safety" dinyatakan bahwa reaksi sistemik berupa rewel (iritabilitas) setelah imunisasi vaksin yang mengandung DTwP adalah mencapai $60 \%$ dan angka kejadian inconsolable crying (menangis terus menerus lebih dari 3 jam) sebesar $1 \%$. Pada uji klinis fase III ditemukan kejadian rewel sebesar 29,8-47,8\% dengan kategori berat sebesar $0,17-0,34 \% .{ }^{8}$ Pada studi PMS di Havana, rewel timbul pada 11,6\%, lebih rendah bila dibanding dengan yang ditemukan pada penelitian ini. ${ }^{13}$ PMS vaksin pentavalen di India menemukan rewel sebesar 28,1-25,4 \% ${ }^{14}$ Reaksi rewel yang ditemukan pada studi ini, meskipun lebih tinggi daripada yang ditemukan pada studi di Havana, namun masih sesuai dengan uji klinis fase III, studi PMS di India, dan jauh dibawah literatur WHO dan tidak ditemukan rewel dengan kategori berat. Kejadian sistemik lain yang ditemukan tiga terbanyak adalah diare, ISPA, dan muntah. Kejadian sistemik lain ini tidak sesuai dengan reaksi pascapemberian vaksin Pentabio ${ }^{\circledR}$ yang dapat terjadi karena merupakan penyakit yang biasa ditemukan pada bayi dan anak seperti yang juga ditemukan pada PMS vaksin pentavalen di Guatemala. ${ }^{12}$

Untuk angka kejadian nyeri pada bekas suntikan bervariasi antara 3,95\% hingga $87,23 \%$ dengan angka tertinggi pada hari ke-1 setelah imunisasi $(87,23 \%)$ dan menurun pada hari ke-2 (36,45\%) serta berikutnya. Mayoritas nyeri yang dirasakan termasuk dalam kategori ringan $(45,45 \%)$. Pada uji klinis fase III ditemukan nyeri bervariasi antara $20,4-47,8 \%{ }^{8}$ Pada studi di Havana ditemukan nyeri sebesar $14,9 \% .{ }^{13} \mathrm{Pada}$ studi di India, nyeri ditemukan 35,9-33,6 \% subjek. ${ }^{14}$

Angka kejadian reaksi lokal kemerahan paling tinggi diketahui pada pengamatan satu hari setelah pemberian imunisasi sebesar 867 $(21,79 \%)$ dengan mayoritas kategori ringan $(20,93 \%)$ dan selanjutnya kejadian kemerahan menurun pada hari berikutnya. Pada uji klinis fase III ditemukan reaksi kemerahan bervariasi antara $10,6 \%$ hingga $17,1 \%{ }^{8}$ Pada PMS vaksin Pentavalen di Havana ditemukan kemerahan pada tempat suntikan sebanyak $5,1 \%$ dan di India $17,2-18,1 \%{ }^{13,14}$ Dengan demikian, kemerahan yang ditemukan pada penelitian ini mirip dengan yang ditemukan pada uji klinis fase III dan studi di India, namun lebih tinggi dibanding dengan yang ditemukan pada studi di Havana.

Angka kejadian reaksi lokal pembengkakan tertinggi diketahui pada pengamatan satu hari sesudah pemberian imunisasi sebesar 1.484 $(37,31 \%)$ yang umumnya bersifat ringan dan selanjutnya kejadian pembengkakan menurun pada hari berikutnya. Pada uji klinis fase III ditemukan reaksi pembengkakan bervariasi antara $11,3 \%$ hingga $17,2 \% .{ }^{8}$ Pada studi di Havana ditemukan pembengkakan $5,5 \%$, sedangkan studi di India ditemukan pembengkakan sebesar 23,7-22.4\%. ${ }^{13,14}$ Untuk pembengkakan yang ditemukan pada penelitian ini sedikit lebih tinggi 
dibanding dengan yang ditemukan pada studi fase III vaksin ini, dan juga pada studi di Havana serta India.

Pada literatur WHO dijelaskan bahwa reaksi lokal ringan seperti nyeri, kemerahan, dan pembengkakan dilaporkan sekitar 40$80 \%$ setelah imunisasi dengan vaksin yang mengandung DTwP. Reaksi lokal cenderung meningkat pada suntikan berikutnya. Reaksi lokal yang ditimbulkan sangat mungkin berhubungan dengan komponen pertusis pada vaksin DTP. ${ }^{11}$

Apabila dibanding dengan uji klinis fase III, reaksi lokal yang ditemukan pada studi ini umumnya lebih tinggi. Hal ini dapat disebabkan oleh perbedaan petugas yang melakukan pengamatan. Pada fase III pengamatan reaksi lokal dikonfirmasi oleh peneliti terlatih, yaitu spesialis anak dengan jumlah terbatas (hasil pengamatan lebih homogen), sedangkan pada studi ini hasil pengamatan dapat bervariasi karena besarnya jumlah petugas yang terlibat dalam pengamatan reaksi lokal yang merupakan juga keterbatasan pada penelitian ini. Studi pascapemasaran melibatkan jumlah subjek yang sangat besar dan pengamatan tidak mungkin dilakukan oleh spesialis anak karena jumlahnya yang sangat terbatas. Jika dibanding dengan literatur WHO, reaksi lokal yang ditemukan pada studi ini masih sesuai dengan kata lain dapat ditoleransi, namun tidak selalu meningkat pada suntikan berikutnya.

Simpulan, berdasar studi pascapemasaran ini pemberian vaksin Pentabio ${ }^{\circledR}$ pada bayi dapat menimbulkan reaksi lokal dan sistemik yang dapat ditoleransi.

\section{Daftar Pustaka}

1. Kementrian Kesehatan RI. Peraturan Menteri Kesehatan Republik Indonesia Nomor 42 tahun 2013 tentang penyelenggaraan imunisasi. Jakarta: Kemkes RI; 2013.

2. World Health Organization. WHO position paper on Haemophilus influenzae type b conjugate vaccines. (Replaces WHO position paper on Hib vaccines previously published in the Weekly Epidemiological Record). Wkly Epidemiol Rec. 2006;81(47):445-52.

3. Rudan I, Boschi-Pinto C, Biloglav Z, Mulholland K, Campbell H. Epidemiology \& etiology of childhood pneumonia. Bull WHO. 2008;86(5):408-16.

4. Gessner BD, Sedyaningsih ER, Griffiths UK, Sutanto A, Linehan M, Mercer D, dkk.
Vaccine-preventable haemophilus influenza type B disease burden and cost-effectiveness of infant vaccination in Indonesia. Pediatr Infect Dis J. 2008;27(5):438-43.

5. Rusmil K, Fadlyana E, Gunad R, Bachtiar NS, Hadyana. Haemophilus influenza type b/ polyribosylribitol phosphate-tetanus (Hib/ PRP-T) vaccine safety, phase I study. IJIHS. 2015;3(2):55-9.

6. Rusmil K, Fadlyana E, Gunadi R, Bachtiar NS, Hadyana. Safety and Immunogenicity of DTP/HB/Hib combination vaccine: phase I study. Paediatr Indones. 2013;53(6):309-14.

7. Bachtiar NS, Rusmil K, SudigdoadiS, Sukandar H, Kartasasmita CB. The Immunogenicity and safety of the new Indonesian DTwPHB-Hib vaccine compared to DTwP-HB vaccine given with The Hib Vaccine. Paediatr Indones. 2017;57(3):129-37.

8. Rusmil K, Gunardi H, Fadlyana E, Soedjatmiko, Dhamayanti M, Sekartini R, dkk. The immunogenicity, safety, and consistency of an Indonesia combined DTP-HB-Hib vaccine in expanded program on immunization schedule. BMC Pediatr. 2015;15(219):1-10.

9. Heininger U. Standardized case definitions for adverse events following immunization. www.thelancet.com. 2013;381(9885):22501.

10. Gidudu JF, Walco GA, Taddio A, Zemsky WT, Halperin SA, Calugar A, dkk. Immunization site pain: case definition and guidelines for collection, analysis, and presentation of immunization safety data. Vaccine. 2012;30(30):4558-77.

11. Kohl KS, Walop W, Gidudu J, Leslie B, Halperin S, Hammer SJ, dkk. Swelling at or near injection site: case definition and guidelines for collection, analysis and presentation of immunization safety data. Vaccine. 2007;25(31):5858-74.

12. Asturias EJ, Contreras-Roldan IL, Ram M, Gracia-Melgar AJ, Morales-Oquendo V, Hartman K, dkk. Post-authorization safety surveillance of a liquid pentavalent vaccine in Guatemalan children. Vaccine. 2013;31(49):5909-14.

13. Muzio V, Aguilar A, Veliz G, Figueroa N, Diaz K, Perez M, dkk. Postmarketing surveillance of the adverse events folowing immunization with a new pentavalent vaccine (DPT$\mathrm{HB}+\mathrm{Hib}$ ). Proceeding of the $13^{\text {th }}$ International Congress on Infectious Diseases; 2008 June 19-22; Kualalumpur, Malaysia Kualalumpur; IJID; 2008. hlm. e143.

14. Dalvi S, Kulkarni PS, Phadke MA, More SS, 
Julitasari Sundoro: Profil Keamanan setelah Pemberian Dosis Primer Vaksin Pentabio® pada Bayi di Indonesia

Lalwani SK, Jain D, dkk. A comparative clinical study to assess safety and reactogenicity of a DTwP+HB+Hib vaccine. Hum Vaccine Immunother. 2015;11(4):901-7. 